\title{
Toxicity of Two Different Sized Lanthanum Oxides in Cultured Cells and Sprague-Dawley Rats
}

\author{
Cheol-Hong Lim \\ Toxicity Research Team, Occupational Safety and Health Research Institute, KOSHA, Daejeon, Korea
}

(Received April 1, 2015; Revised April 27, 2015; Accepted June 1, 2015)

\begin{abstract}
In recent years, the use of both nano- and micro-sized lanthanum has been increasing in the production of optical glasses, batteries, alloys, etc. However, a hazard assessment has not been performed to determine the degree of toxicity of lanthanum. Therefore, the purpose of this study was to identify the toxicity of both nano- and micro-sized lanthanum oxide in cultured cells and rats. After identifying the size and the morphology of lanthanum oxides, the toxicity of two different sized lanthanum oxides was compared in cultured RAW264.7 cells and A549 cells. The toxicity of the lanthanum oxides was also analyzed using rats. The half maximal inhibitory concentrations of micro- $\mathrm{La}_{2} \mathrm{O}_{3}$ in the RAW264.7 cells, with and without sonication, were 17.3 and 12.7 times higher than those of nano- $\mathrm{La}_{2} \mathrm{O}_{3}$, respectively. Similar to the RAW264.7 cells, the toxicity of nano- $\mathrm{La}_{2} \mathrm{O}_{3}$ was stronger than that of micro- $\mathrm{La}_{2} \mathrm{O}_{3}$ in the A549 cells. We found that nano- $\mathrm{La}_{2} \mathrm{O}_{3}$ was absorbed in the lungs more and was eliminated more slowly than micro- $\mathrm{La}_{2} \mathrm{O}_{3}$. At a dosage that did not affect the body weight, numbers of leukocytes, and concentrations of lactate dehydrogenase and albumin in the bronchoalveolar lavage (BAL) fluids, the weight of the lungs increased. Inflammatory effects on BAL decreased over time, but lung weight increased and the proteinosis of the lung became severe over time. The effects of particle size on the toxicity of lanthanum oxides in rats were less than in the cultured cells. In conclusion, smaller lanthanum oxides were more toxic in the cultured cells, and sonication decreased their size and increased their toxicity. The smaller-sized lanthanum was absorbed more into the lungs and caused more toxicity in the lungs. The histopathological symptoms caused by lanthanum oxide in the lungs did not go away and continued to worsen until 13 weeks after the initial exposure.
\end{abstract}

Key words: Lanthanum oxide, Nano, Particle size, Toxicity

\section{INTRODUCTION}

Lanthanum is a rare earth element (REE) that includes 15 lanthanides plus scandium and yttrium. As REEs are difficult to separate, until the early $20^{\text {th }}$ century, they were mainly used in mixed forms. At that time, REEs containing lanthanum began to be used extensively in carbon lighting applications, such as studio lighting and cinema projection. As a result, increased cases of lung disease were reported among photoengravers, lithographers, and movie projec-

Correspondence to: Cheol-Hong Lim, Toxicity Research Team, Occupational Safety and Health Research Institute, KOSHA, 339-30, Expo-ro, Yuseong-gu, Daejeon 305-380, Korea E-mail: limch@kosha.net

This is an Open-Access article distributed under the terms of the Creative Commons Attribution Non-Commercial License (http:// creativecommons.org/licenses/by-nc/3.0) which permits unrestricted non-commercial use, distribution, and reproduction in any medium, provided the original work is properly cited. tionists who were exposed to fumes containing lanthanum $(1,2)$.

Today, high-purity lanthanum can be produced and is used in catalysts, magnets, metallurgical alloys, phosphors, glass, etc. More than 15,000 tons of lanthanum is used annually worldwide in nickel-metal hydride batteries, hydrogen sponge alloys, camera and telescopic lenses, and petroleum cracking catalysts (3).

Cerium is the most commonly used REE, followed by lanthanum and then neodymium. Therefore, most toxicological studies on REEs have focused on the evaluation of cerium compounds. However, lanthanum is also used in significant amounts (4-7), but only a few comparative toxicity studies of lanthanum and other REEs have been conducted. For example, Palmer et al. compared the toxicity of lanthanum chloride, cerium chloride, neodymium chloride, lanthanum oxide, cerium oxide, and neodymium chloride in a cell culture system (8). Comparative toxicity studies of lanthanum and other REEs have also been conducted in 
vivo systems (9-12).

Therefore, the purpose in this study was to verify the toxicity of lanthanum. Because it is possible that nano-sized lanthanum has a higher toxicity level than micro-sized lanthanum and because nano-sized lanthanum use has been increasing in the workplace, a comparative toxicity study of nano-sized and micro-sized lanthanum was conducted.

\section{MATERIALS AND METHODS}

Particles. This study used micro- $\mathrm{La}_{2} \mathrm{O}_{3}$ (Sigma-Aldrich 199923, MO, USA) and nano- $\mathrm{La}_{2} \mathrm{O}_{3}$ (Sigma-Aldrich 634271, $<100 \mathrm{~nm}$ ) powders. The morphologies of the lanthanum oxides particles were observed using transmission electron microscopy (JEM2100F, JEOL, Japan). The specific surface areas of the experimental materials were measured using the Brunauer-Emmett-Teller (BET) method at the Korea Research Institute of Chemical Technology (Daejeon, Korea). Stock suspensions $(4 \mathrm{mg} / \mathrm{mL})$ of lanthanum oxides were prepared in distilled water (for the cell study) or in saline (for the animal study) and sonicated for $20 \mathrm{sec}$ with a probe-type ultrasonicator (Sonics \& Materials Inc., VC750, Newtown, CT, USA) at an amplitude setting of $40 \%$. The hydrodynamic diameters were measured using the dynamic light scattering method (Zetasizer Nano ZS 90, Malvern, UK).

Cell culture. Mouse macrophage-like RAW264.7 cells and human alveolar basal epithelial A549 cells were used in the study. The RAW264.7 cells were grown in Dulbecco's modified eagle medium (Gibco 12800-017, Grand Island, NY, USA), supplemented with $1.5 \mathrm{~g}$ of sodium bicarbonate (Sigma-Aldrich S-5761), 100 unit/mL of penicillin/streptomycin (Gibco 15140-122, Grand Island, NY, USA), and $100 \mathrm{~mL}$ of fetal bovine serum (FBS; Hyclone SH 30919.03, South Logan, UT, USA). The cell passage was performed at 3- to 4-day intervals with a plastic scraper (Thermo Fisher Scientific, Rochester, NY, USA). The A549 cells were grown in the Roswell Park Memorial Institute (RPMI) 1640 medium (Gibco 31800-014), supplemented with $2 \mathrm{~g}$ of sodium bicarbonate, 100 unit/mL of penicillin/streptomycin, and $100 \mathrm{~mL}$ of FBS. The cell passage was performed at 3 - to 4 -day intervals with a $0.25 \%$ Trypsin-EDTA solution for rinse the cell layer (Gibco, 25200-072) and a TrypsinEDTA solution for cell separation (Sigma-Aldrich, T 3924). The cells were incubated in a Forma direct heat $\mathrm{CO}_{2}$ incubator (Marietta, $\mathrm{OH}, \mathrm{USA}$ ) with $5 \% \mathrm{CO}_{2}$ at $37^{\circ} \mathrm{C}$.

Cytotoxicity assay. A cytotoxicity assay was performed using cells from passages 5 to 15 . Then, $100 \mu \mathrm{L}$ of $1 \times 10^{6}$ cells/mL of separated cells was seeded in a 96-well culture plate (Charles River Endosafe $\AA$ M9005, Charleston, SC, USA). Various concentrations of lanthanum oxides were then added to the plate and incubated for $48 \mathrm{hr}$ in the $\mathrm{CO}_{2}$ incubator. After $48 \mathrm{hr}$ of incubation, the plates were washed with $300 \mu \mathrm{L}$ of Dulbecco's phosphate buffered saline (SigmaAldrich D-5652) and $200 \mu \mathrm{L}$ of phenol red-free RPMI solution (Gibco, 11835-030) containing 10\% alamarBlue $^{\mathrm{TM}}$ (Invitrogen, Carlsbad, CA, USA) was added. After incubation for another $4 \mathrm{hr}$, the fluorescence (an excitation of $530 \mathrm{~nm}$ and an emission of $580 \mathrm{~nm}$ ) of the plates was measured with a microplate reader (Biotec Synergy H1, Winooski, VT, USA).

Animals. Seven-week-old male specific pathogen-free Sprague-Dawley (SD) rats were obtained from Central Lab Animal, Inc. (Seoul, Korea). Rats were housed in a room with controlled temperature $\left(23^{\circ} \mathrm{C} \pm 2^{\circ} \mathrm{C}\right)$ and humidity $(50 \pm 10 \%)$ and a 12-hr light/dark cycle. Rats were fed with filtered water and a rodent diet (LabDiet 5053, PMI Nutrition, St. Louis, MO, USA) ad libitum. After a 2-week acclimation period, the rats were administered $5 \mathrm{mg} / \mathrm{kg}$ of micro$\mathrm{La}_{2} \mathrm{O}_{3}$ or nano- $\mathrm{La}_{2} \mathrm{O}_{3}$ after slight anesthesia with a mixture of Zoletil 50 (Viebac, France) and 2\% Rampan (Bayer, Germany). General clinical symptoms, such as eye, skin, respiration, and pattern of movement were observed during the experimental period. Three days, 4 weeks, or 13 weeks after the exposure, the rats were anesthetized with isoflurane (Ilsung Pharmaceuticals Co., Seoul, Korea) and blood was collected from their abdominal aortas. This study was approved by the animal ethics committee to ensure appropriate animal care during research.

Bronchoalveolar lavage. The tracheae were cannulated, and the lungs were lavaged five times with $3 \mathrm{~mL}$ of calcium- and magnesium-free phosphate buffered saline (PBS, $\mathrm{pH}$ 7.4). The lavaged fluids were centrifuged at 1,500 rpm for $10 \mathrm{~min}$ (Hanil Union 32R, Incheon, Korea). The supernatants were stored at $-80^{\circ} \mathrm{C}$ for a later protein and lactate dehydrogenase (LDH) assay. The number of the precipitated cells was counted with a Coulter counter (Drew Science, Hemarvet 850, Miami Lakes, FL, USA), and the cells were then centrifuged with a Cyto centrifuge (Hanil Cellspin, Incheon, Korea). The centrifuged cells were stained with a Diff-Quick staining solution (Sysmex, Kobe, Japan), and differential counts of macrophages and polymorphonuclear leukocytes (PMNs) were conducted by counting approximately 300 cells under a microscope at a magnification of 100 times. The LDH and albumin in the lavage fluid were measured using a biochemistry analyzer (Toshiba TBA 20FR, Tokyo, Japan).

Measurement of lanthanum levels. Lung, liver, and brain tissues were digested in 10-fold of $65 \%$ nitric acid (Merck, Whitehouse Station, NJ, USA), and the levels of lanthanum were measured using Inductively Coupled Plasma Mass Spectrometry (Agilent Technologies 7500CE, Santa Clara, CA, USA). Lanthanum in the serum was measured in 
5-fold nitric acid.

Histopathology. Lungs were fixed in a $10 \%$ formalin solution containing neutral PBS and embedded in paraffin. After being stained with hematoxylin and eosin or Masson's trichrome, lung samples were examined in a light microscopy at a magnification of 100 times.

Statistical analysis. Data were analyzed using ANOVA followed by post hoc analysis based on Duncan's multiple range test to determine the differences between the compared groups. Statistical analyses were performed using SigmaPlot 12 (Systat Software Inc., San Jose, CA, USA). Differences were considered significant when the $p$-value was $<0.05$.

\section{RESULTS}

Identification of Ianthanum oxides. The BET specific surface areas of the micro- $\mathrm{La}_{2} \mathrm{O}_{3}$ and nano- $\mathrm{La}_{2} \mathrm{O}_{3}$ were $0.95 \mathrm{~m}^{2} / \mathrm{g}$ and $7.66 \mathrm{~m}^{2} / \mathrm{g}$, respectively; these surface areas correspond to the primary particle sizes as $869.6 \mathrm{~nm}$ and $103.6 \mathrm{~nm}$, respectively (Table 1). The agglomerated lantha-
Table 1. Brunauer-Emmett-Teller (BET) surface area and calculated equivalent primary particle size of two lanthanum oxides

\begin{tabular}{lcc}
\hline \hline Parameter & Micro- $-\mathrm{La}_{2} \mathrm{O}_{3}$ & Nano- $\mathrm{La}_{2} \mathrm{O}_{3}$ \\
\hline BET surface area $\left(\mathrm{m}^{2} / \mathrm{g}\right)$ & 0.95 & 7.66 \\
Calculated equivalent particle size $(\mathrm{nm})$ & 869.6 & 103.6
\end{tabular}

*Diameter $=6,000 /(\mathrm{BET} \cdot \rho)$, where $\rho=7.31 \mathrm{~g} / \mathrm{cm}^{3}$.

num oxides were observed in the transmission electron microscopy images. The heavily agglomerates in the distilled water and saline became smaller and looked little aciniforms following sonication (Fig. 1). The hydrodynamic diameter of the micro- $\mathrm{La}_{2} \mathrm{O}_{3}$ particles was $1,487 \mathrm{~nm}$, whereas for the nano- $\mathrm{La}_{2} \mathrm{O}_{3}$ particles, it was $326.8 \mathrm{~nm}$. After sonication for $20 \mathrm{sec}$, the hydrodynamic diameter of the micro- $\mathrm{La}_{2} \mathrm{O}_{3}$ and nano- $\mathrm{La}_{2} \mathrm{O}_{3}$ particles decreased to 364.3 and $80.4 \mathrm{~nm}$, respectively (Fig. 2)

Effect of lanthanum oxide in the cultured cells. The effects of the lanthanum oxides on the RAW264.7 and A549 cells are presented in Fig. 3, and the results are summarized in Table 2. The RAW264.7 cells were more sensitive to the lanthanum oxides than the A549 cells. The half
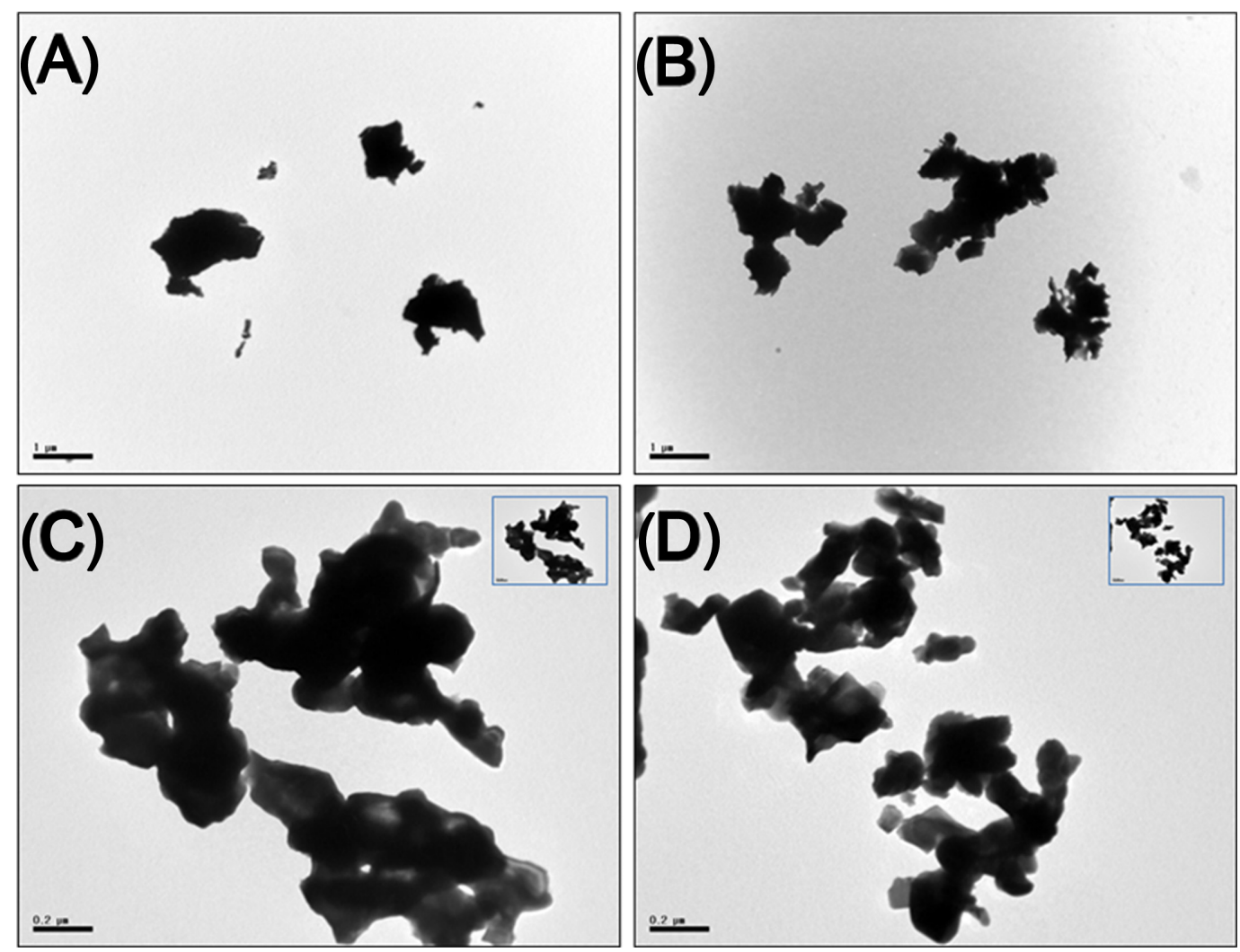

Fig. 1. Comparison of transmission electron microscopy images of two lanthanum oxide particles. Micro-La $\mathrm{O}_{3}(A, B)$ and nano-La $\mathrm{O}_{3}$ $(C, D)$ were dispersed in distilled water with $(B, D)$ or without sonication $(A, C)$. The images of micro- $\mathrm{La}_{2} \mathrm{O}_{3}$ were taken at a magnification of 10,000 times, and the images of nano- $\mathrm{La}_{2} \mathrm{O}_{3}$ were taken at a magnification of 50,000 times. The inset boxes in $\mathrm{C}$ and $\mathrm{D}$ correspond to the magnification of $A$ and $B$. 
(A)

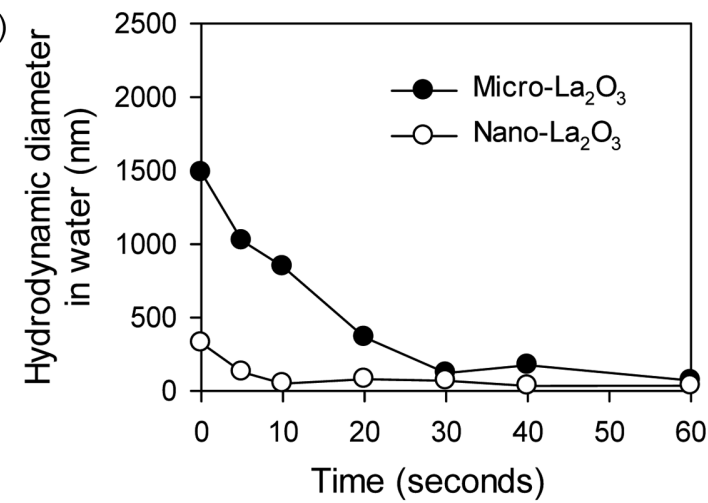

(C)

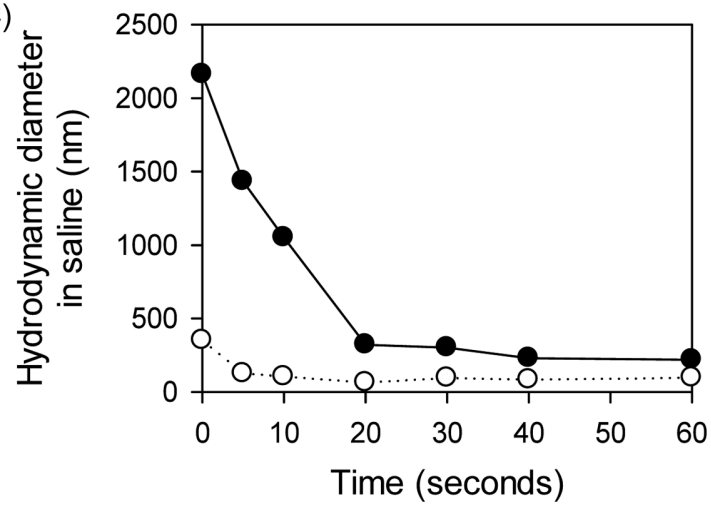

(B)

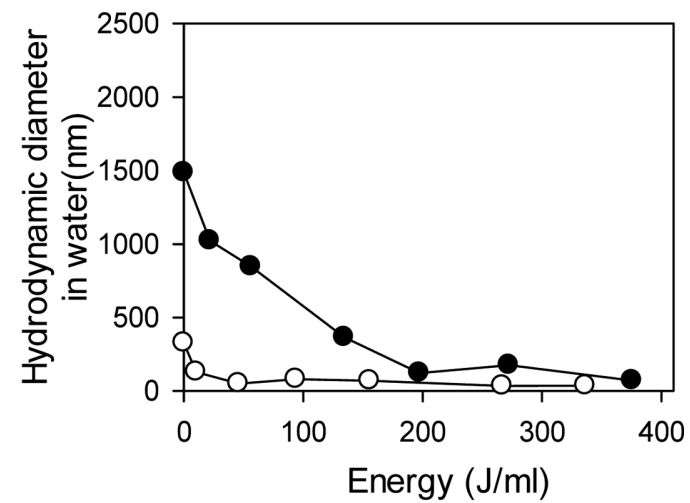

(D)

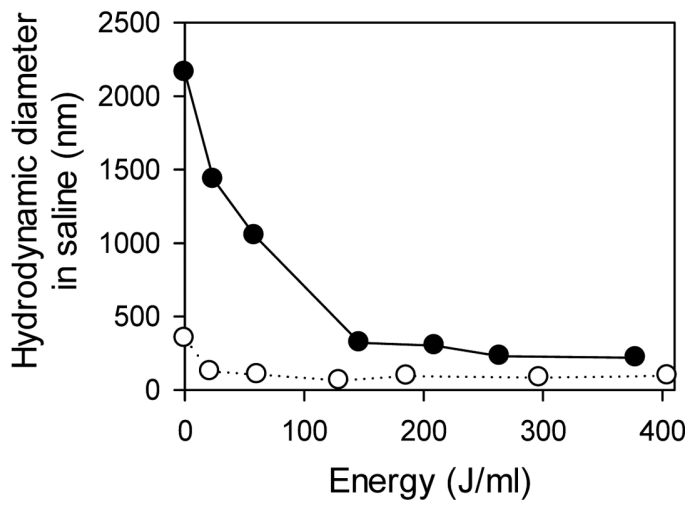

Fig. 2. Hydrodynamic diameters of the two lanthanum oxides dispersed in distilled water $(A, B)$ and saline $(C, D)$ as a function of the sonication time $(A, C)$ and energy $(B, D)$.

maximal inhibitory concentrations $\left(\mathrm{IC}_{50}\right)$ of micro- $\mathrm{La}_{2} \mathrm{O}_{3}$ and nano- $\mathrm{La}_{2} \mathrm{O}_{3}$ in the RAW264.7 cells were $26.5 \mu \mathrm{g} / \mathrm{mL}$ and $2.08 \mu \mathrm{g} / \mathrm{mL}$, respectively, and $172.9 \mu \mathrm{g} / \mathrm{mL}$ and $50.6 \mu \mathrm{g} / \mathrm{mL}$ in the A549 cells, respectively. When the toxicity was compared according to particle size, the toxicity of nano- $\mathrm{La}_{2} \mathrm{O}_{3}$ was more severe than that of micro- $\mathrm{La}_{2} \mathrm{O}_{3}$. The $\mathrm{IC}_{50}$ of nano$\mathrm{La}_{2} \mathrm{O}_{3}$ was 12.7 times lower than that of micro- $\mathrm{La}_{2} \mathrm{O}_{3}$ when the lanthanum oxides were unsonicated. Sonication also increased the toxicity of the lanthanum oxides. The $\mathrm{IC}_{50}$ of the sonicated micro- $\mathrm{La}_{2} \mathrm{O}_{3}$ and nano- $\mathrm{La}_{2} \mathrm{O}_{3}$ decreased 6.4 times and 8.7 times, respectively, in the RAW264.7 cells and 6.1 times and 14.1 times, respectively, in the A549 cells.

Effect of lanthanum oxide in the rats. The administered lanthanum oxides were not detected in the serum and brain and were only minimally present in the liver. Interestingly, the nano- $\mathrm{La}_{2} \mathrm{O}_{3}$ level was much higher in the lung compared to micro- $\mathrm{La}_{2} \mathrm{O}_{3}$ (Fig. 4). There were no significant differences in body weight gains and clinical symptoms from the lanthanum oxides. However, severe effects were observed in other parameters. In the BAL fluid at 3 days after administration, the number of total leukocytes was 7.1 times higher in the micro- $\mathrm{La}_{2} \mathrm{O}_{3}$-exposed rats and 10.3 times higher in the nano- $\mathrm{La}_{2} \mathrm{O}_{3}$-exposed rats compared with normal control. These increased total leukocyte counts decreased fast in the micro- $\mathrm{La}_{2} \mathrm{O}_{3}$-exposed rats, whereas it took more time for them to decrease in the nano- $\mathrm{La}_{2} \mathrm{O}_{3}$ exposed rats. In addition, the ratio of PMNs increased to approximately $70 \%$ by the instillation of both the lanthanum oxides, and this did not decrease until 13 weeks after administration (Fig. 5). Concentrations of albumin in the BAL fluid at 3 days after administration were 2.2 times higher in the micro- $\mathrm{La}_{2} \mathrm{O}_{3}$-exposed rats and 4.3 times higher in the nano- $\mathrm{La}_{2} \mathrm{O}_{3}$-exposed rats compared with the normal control, and the LDH level was 5.5 times higher in the micro- $\mathrm{La}_{2} \mathrm{O}_{3}$-exposed rats and 10.3 times in the nano$\mathrm{La}_{2} \mathrm{O}_{3}$-exposed rats. Although statistical differences were not found between the control and lanthanum oxide-exposed rats at 13 weeks postexposure, increased albumin and LDH levels were still present (Table 3). The weight of the rats' lungs was heavier at 13 weeks than at 3 days (Table 4). In addition, alveolar proteinosis was found in the lanthanum oxide-exposed rats. Similar to lung weight, the histopathological symptoms were also more severe in the rats at 13 weeks than at 3 days. Overall, the symptoms were slightly more severe in the nano- $\mathrm{La}_{2} \mathrm{O}_{3}$-exposed rats than in the micro- $\mathrm{La}_{2} \mathrm{O}_{3}$-exposed rats (Fig. 6).

\section{DISCUSSION}

The research and development of nano-sized metal oxides is increasing in many growing industries (3). Therefore, 
(A)
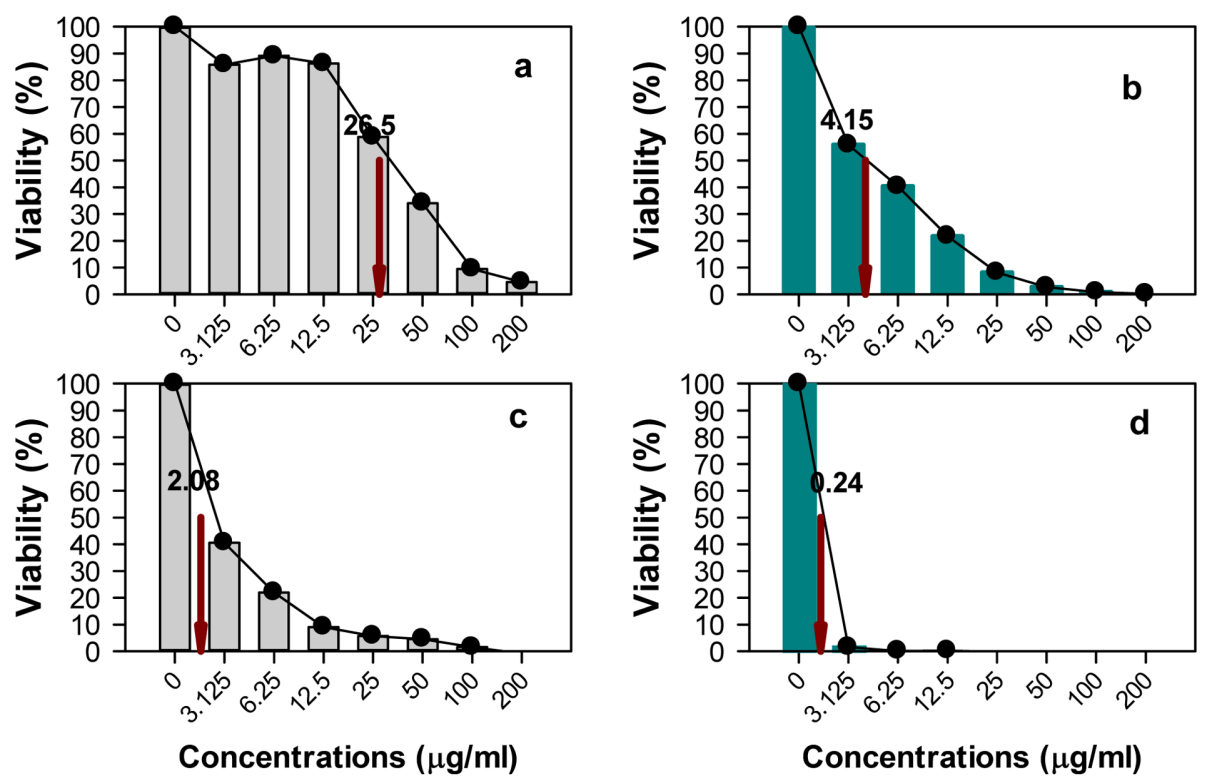

(B)
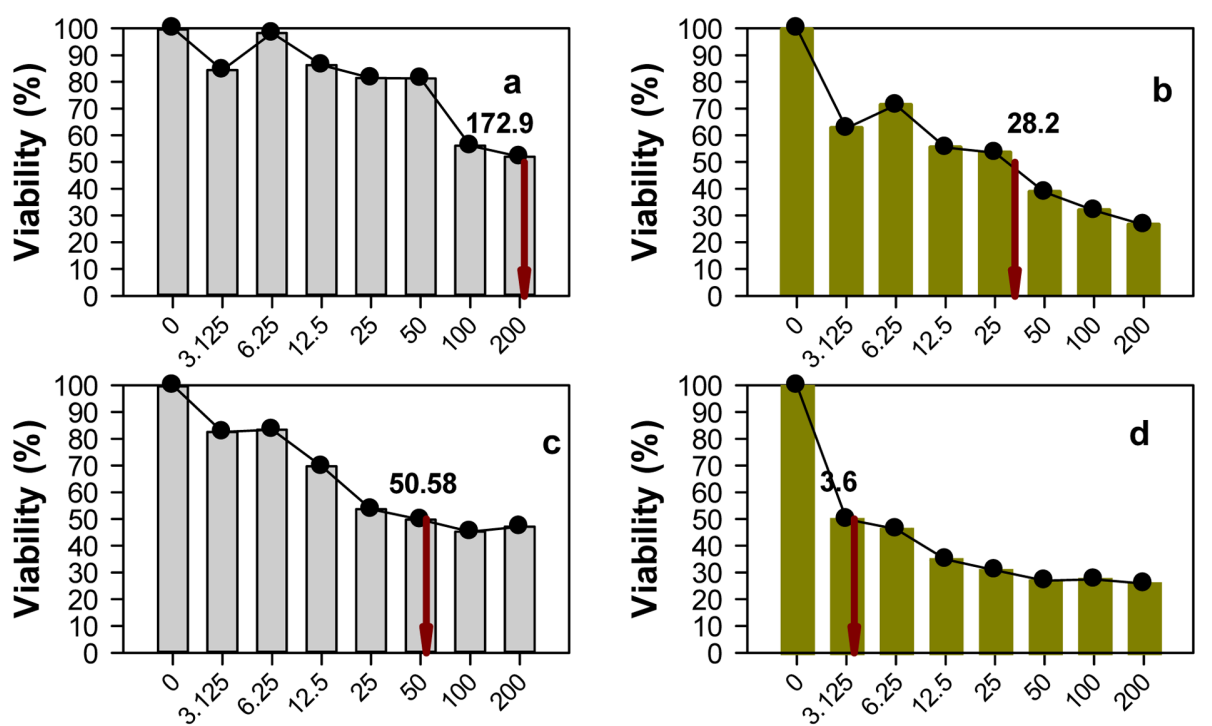

Concentrations $(\mu \mathrm{g} / \mathrm{ml})$

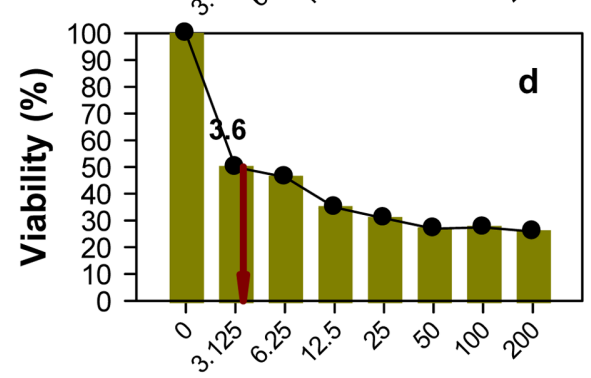

Concentrations $(\mu \mathrm{g} / \mathrm{ml})$

Fig. 3. Cytotoxicity of the two lanthanum oxides in RAW264.7 cells (A) and $A 549$ cells (B). Toxicity was determined with an alamarBlue assay. a, micro- $\mathrm{La}_{2} \mathrm{O}_{3}$ without sonication; b, micro- $\mathrm{La}_{2} \mathrm{O}_{3}$ with sonication; $c$, nano- $\mathrm{La}_{2} \mathrm{O}_{3}$ without sonication; $d$, nano- $\mathrm{La}_{2} \mathrm{O}_{3}$ with sonication.

Table 2. Comparison of the toxicities of two lanthanum oxides in RAW264.7 and A549 cells

\begin{tabular}{llcc}
\hline \hline \multirow{2}{*}{ Cell line } & \multirow{2}{*}{ Sonication } & \multicolumn{2}{c}{$\mathrm{IC}_{50}(\mu \mathrm{g} / \mathrm{mL})$} \\
\cline { 3 - 4 } & & $\mathrm{Micro}_{\mathrm{La}} \mathrm{O}_{3}$ & $\mathrm{Nano}^{-\mathrm{La}_{2} \mathrm{O}_{3}}$ \\
\hline \multirow{2}{*}{ RAW264.7 } & No & 26.5 & 2.08 \\
& Yes & 4.15 & 0.24 \\
\hline \multirow{2}{*}{$\mathrm{A} 549$} & No & 172.9 & 50.6 \\
& Yes & 28.2 & 3.6 \\
\hline
\end{tabular}

identifying the hazards of metal oxides that are in the form of nano-sized materials has become an important issue for controlling potential harm caused by the presence of metal oxides in the workplace. The use of REEs has dramatically increased, including both micro- and nano-sized particles. However, the toxicities of REEs have not been fully investigated except for cerium oxide, which was included on the list of 13 nanomaterials identified as hazards by the Working Party on Manufactured Nanomaterials (WPMN) of the 

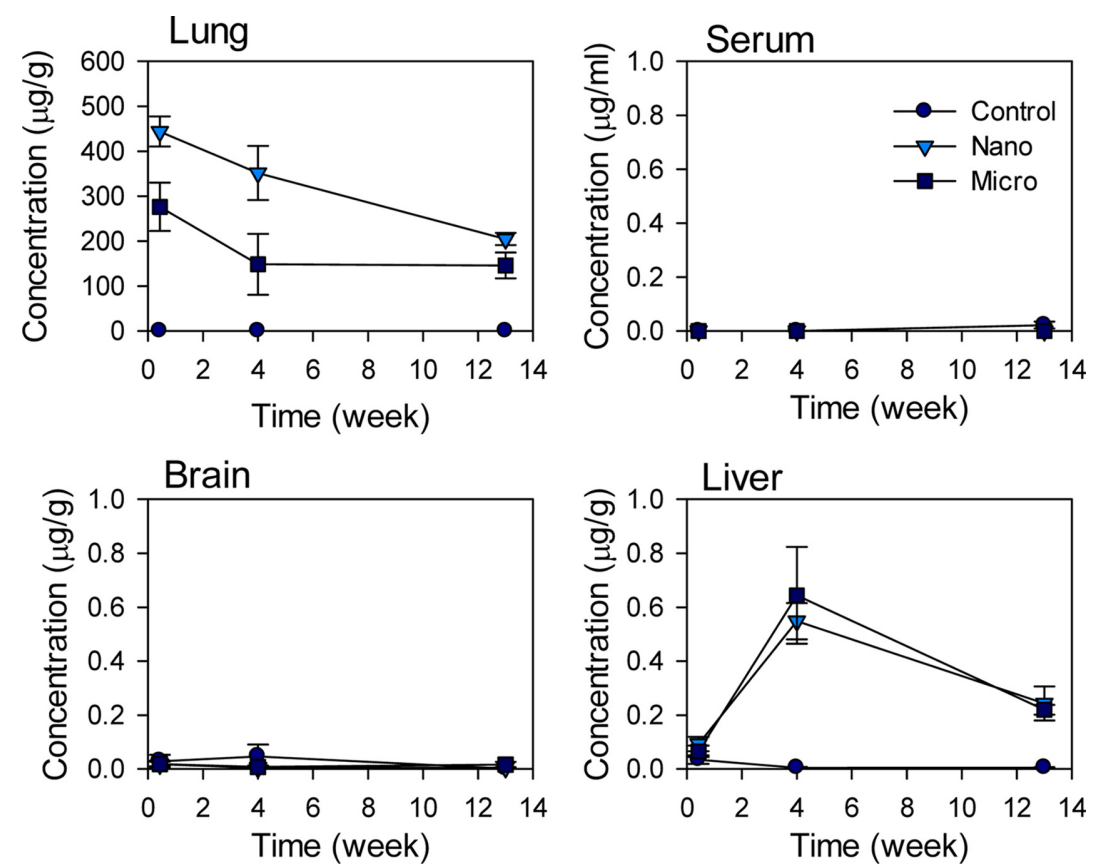

Fig. 4. Distribution of lanthanum oxide in several organs and the serum. Error bars indicate the standard error. Five rats were used for each group at 3 days, and six rats were used at 4 weeks and 13 weeks.
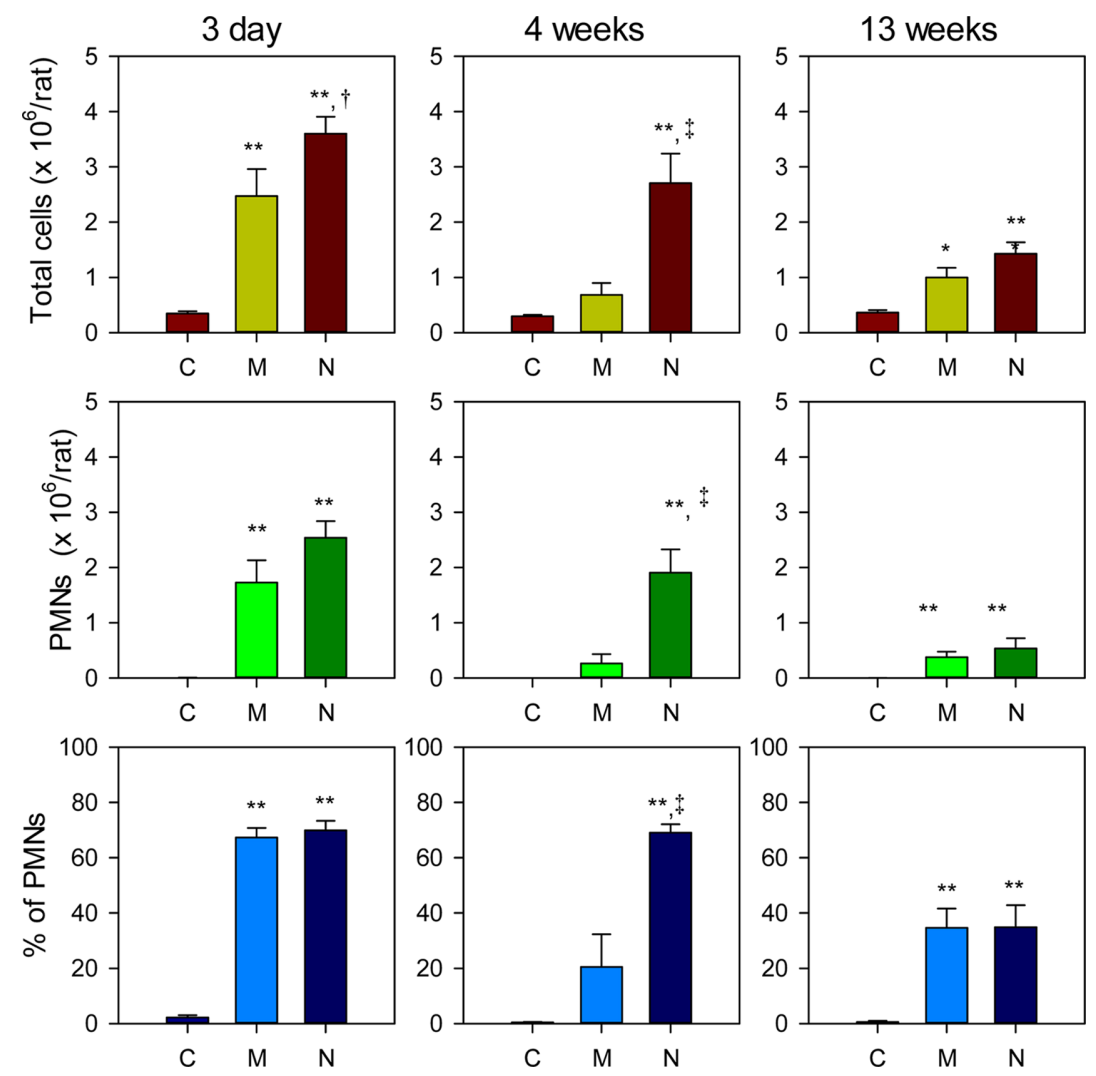

Fig. 5. Differential cell counts of leukocytes in the BAL fluid of rats exposed to the two lanthanum oxides. Error bars indicate the standard error. $P$-values were calculated using Duncan's multiple range method. ${ }^{*}, p<0.05$ versus control; ${ }^{* *}, p<0.01$ versus control; $\dagger$, $p<0.05$ versus micro-lanthanum oxide; $\neq, p<0.01$ versus micro-lanthanum. $\mathrm{C}$, control; $\mathrm{M}, \mathrm{micro}-\mathrm{La}_{2} \mathrm{O}_{3} ; \mathrm{N}$, nano-La $\mathrm{O}_{3}$. Five rats were used for each group at 3 days, and six rats were used at 4 weeks and 13 weeks. 
Table 3. Effects of the two lanthanum oxides on the biochemical constituents in bronchoalveolar lavage fluid

\begin{tabular}{cllcc}
\hline \hline \multirow{2}{*}{ Experiment } & Parameter & Control & Micro-La $\mathrm{O}_{3}$ & $\mathrm{Nano}^{2}-\mathrm{La}_{2} \mathrm{O}_{3}$ \\
\hline \multirow{2}{*}{3 days } & Albumin $(\mu \mathrm{g} / \mathrm{dL})$ & $5.80 \pm 2.17$ & $12.80 \pm 2.77^{*}$ & $25.00 \pm 5.24^{* *, *}$ \\
& $\mathrm{LDH}(\mathrm{unit} / \mathrm{L})$ & $42.0 \pm 71.7$ & $230.8 \pm 157.9^{*}$ & $433.0 \pm 65.5^{* *, *}$ \\
\hline \multirow{2}{*}{4 weeks } & Albumin $(\mu \mathrm{g} / \mathrm{dL})$ & $6.83 \pm 4.26$ & $11.83 \pm 4.75$ & $33.5 \pm 15.95^{* *, *}$ \\
& $\mathrm{LDH}(\mathrm{unit} / \mathrm{L})$ & $10.7 \pm 7.5$ & $36.3 \pm 37.2$ & $153.8 \pm 63.8^{* *, *}$ \\
\hline \multirow{2}{*}{13 weeks } & Albumin $(\mu \mathrm{g} / \mathrm{dL})$ & $1.67 \pm 1.21$ & $5.50 \pm 3.83$ & $7.67 \pm 5.65$ \\
& $\mathrm{LDH}($ unit/L) & $3.46 \pm 3.66$ & $17.01 \pm 17.84$ & $32.67 \pm 49.21$ \\
\hline
\end{tabular}

Values present the mean \pm standard deviation.

$P$-values were calculated using Duncan's multiple range method: ${ }^{*}, p<0.05$ versus control; ${ }^{* *}, p<0.01$ versus control; ${ }^{\dagger}, p<0.05$ versus Micro$\mathrm{La}_{2} \mathrm{O}_{3}{ }^{\ddagger}, p<0.01$ versus Micro- $\mathrm{La}_{2} \mathrm{O}_{3}$.

Five rats were used for each group at 3 days, and six rats were used at 4 weeks and 13 weeks.

Table 4. Effects of the two lanthanum oxides on the weight of the lungs(unit; gram)

\begin{tabular}{|c|c|c|c|c|}
\hline Experiment & Method & Control & Micro- $\mathrm{La}_{2} \mathrm{O}_{3}$ & Nano- $\mathrm{La}_{2} \mathrm{O}_{3}$ \\
\hline \multirow{3}{*}{3 days } & Left lung & $0.41 \pm 0.03$ & $0.43 \pm 0.02$ & $0.48 \pm 0.04^{*, \hat{\dagger}}$ \\
\hline & Right lung & $1.29 \pm 0.07$ & $1.23 \pm 0.11$ & $1.36 \pm 0.07$ \\
\hline & Total & $1.70 \pm 0.07$ & $1.65 \pm 0.12$ & $1.83 \pm 0.09^{\dagger}$ \\
\hline \multirow{3}{*}{4 weeks } & Left lung & $0.48 \pm 0.03$ & $0.60 \pm 0.16$ & $0.79 \pm 0.15^{* *, ;}$ \\
\hline & Right lung & $1.47 \pm 0.07$ & $1.57 \pm 0.19$ & $1.91 \pm 0.16^{* * *}$ \\
\hline & Total & $1.94 \pm 0.08$ & $2.16 \pm 0.33$ & $2.71 \pm 0.31^{* *,}$ \\
\hline \multirow{3}{*}{13 weeks } & Left lung & $0.53 \pm 0.04$ & $0.72 \pm 0.12^{* * *}$ & $0.75 \pm 0.11^{* *}$ \\
\hline & Right lung & $1.70 \pm 0.13$ & $1.94 \pm 0.11^{*}$ & $2.08 \pm 0.20^{* *}$ \\
\hline & Total & $2.23 \pm 0.15$ & $2.65 \pm 0.13^{* *}$ & $2.83 \pm 0.31^{* * *}$ \\
\hline
\end{tabular}

Values present the mean \pm standard deviation.

$P$-values were calculated using Duncan's multiple range method: ${ }^{*}, p<0.05$ versus control; ${ }^{* *}, p<0.01$ versus control; ${ }^{\dagger}, p<0.05$ versus Micro$\mathrm{La}_{2} \mathrm{O}_{3} ;{ }^{\ddagger}, p<0.01$ versus Micro- $\mathrm{La}_{2} \mathrm{O}_{3}$.

Five rats were used for each group at 3 days, and six rats were used at 4 weeks and 13 weeks.

(A)

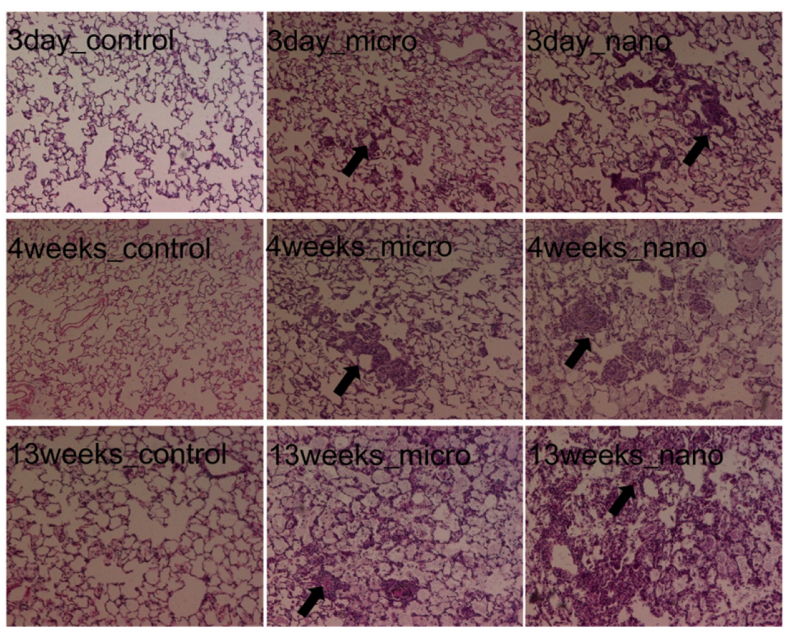

(B)

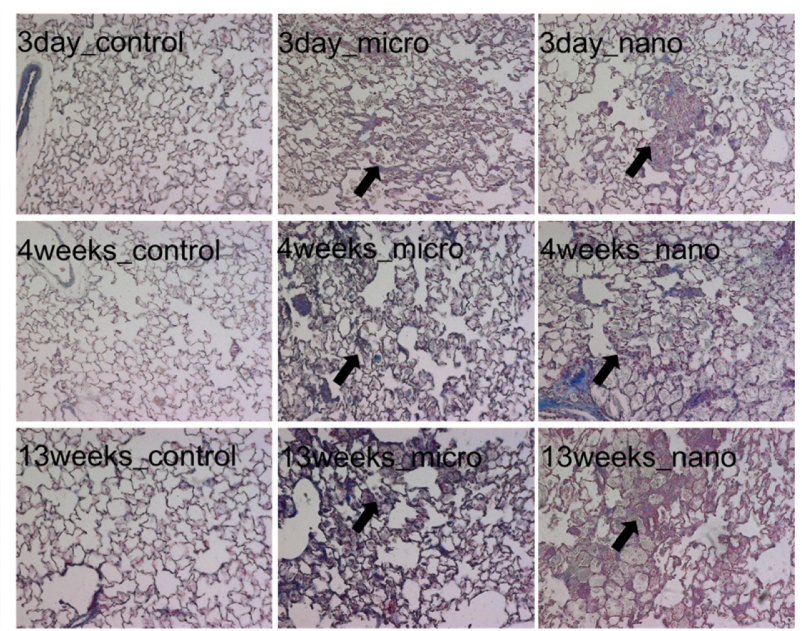

Fig. 6. Histopathology of the lungs exposed to nano- and/or micro-sized lanthanum oxide. Lungs were stained with Hematoxylin and eosin (A) or Masson's trichrome (B). Pictures were taken at a magnification of 100 times. Arrows show alveolar proteinosis of the lung. Five rats were used for each group at 3 days, and six rats were used at 4 weeks and 13 weeks.

OECD (13). Lanthanum oxide is similar to cerium oxide in many ways. In fact, in the past, they were commonly used together and/or interchangeably. Their structures, purposes, and usage are all similar. However, few studies have investigated the potential toxicity of lanthanum, while many reports have focused on the toxicity of cerium in both nano- 
and micro-sized particles.

In this study, two lanthanum oxide powders (micro- $\mathrm{La}_{2} \mathrm{O}_{3}$ and nano- $\mathrm{La}_{2} \mathrm{O}_{3}$ ) were analyzed. At first, the differences in size and shape of the micro- $\mathrm{La}_{2} \mathrm{O}_{3}$ and nano- $\mathrm{La}_{2} \mathrm{O}_{3}$ particles were identified visually through a transmission electron microscopy examination and the specific surface areas were measured. A comparative toxicity study was then performed because the primary particle sizes of the micro- $\mathrm{La}_{2} \mathrm{O}_{3}$ and nano- $\mathrm{La}_{2} \mathrm{O}_{3}$ were estimated to clearly different (Table 1). The differences in particle size and shape between the micro- $\mathrm{La}_{2} \mathrm{O}_{3}$ and nano- $\mathrm{La}_{2} \mathrm{O}_{3}$ were then confirmed (Fig. 1).

In the cytotoxicity assay, mouse macrophage-like RAW264.7 cells and human alveolar basal epithelial A549 cells were used because inhaled particles are generally exposed to the macrophages at first and they are also exposed to the alveolar epithelial cells if they are not eliminated by the respiratory defense system.

The toxicity of lanthanum oxides was found to be increased in the cultured cell system if the particle sizes become smaller. Sonicated lanthanum oxides were also more toxic. The toxicity of the lanthanum oxides to the A549 cells was less potent than to the RAW264.7 cells. However, the effects of the particle size on the cultured cells were similar. Our toxicity results in the cell culture system were clearly consistent with many other studies that have reported that the toxicity of low-toxicity, low-solubility particles increases when the particle sizes decrease and/or their surface area increases $(14,15)$.

Similar to the cultured cells, the toxicity of nano- $\mathrm{La}_{2} \mathrm{O}_{3}$ in the lung was more severe than micro- $\mathrm{La}_{2} \mathrm{O}_{3}$. At the dose that caused no significant clinical symptoms (i.e., body weight changes), significant lung damage was observed. For example, leukocyte counts and cell damage indicators in the BAL fluid were significantly changed. The inflammation pattern from the lanthanum oxides was similar to the elimination of lanthanum oxides from the lung. A higher concentration of lanthanum was measured in the lung of the nano- $\mathrm{La}_{2} \mathrm{O}_{3}$-exposed rats than in the micro- $\mathrm{La}_{2} \mathrm{O}_{3}$-exposed rats. Also, elimination was faster in the micro- $\mathrm{La}_{2} \mathrm{O}_{3}$-exposed rats than in the nano- $\mathrm{La}_{2} \mathrm{O}_{3}$-exposed rats.

Unlike the inflammatory effect and elimination pattern of lanthanum in the lung, lung weight at 13 weeks was heavier than at 3 days (Table 4). The alveolar proteinosis of the lung was more severe after 13 weeks compared 3 days. The severity of lung symptoms was only slightly higher in the nano- $\mathrm{La}_{2} \mathrm{O}_{3}$-exposed rats than the micro- $\mathrm{La}_{2} \mathrm{O}_{3}$-exposed rats (Fig. 6). The possible mechanism of lung damage was not determined in this study. However, there is a strong possibility that oxidative damage played a role in the damage to the lungs. Hong et al. (2015) recently reported that oxidative damage was caused in mice administered lanthanum chloride (16).

Overall, this study suggests that the particle size significantly influences the toxicity of lanthanum oxide. This effect was prominent in the cultured cells. Particle size also influenced the elimination pattern of lanthanum and its effects in the lungs of rats. However, the size effects in the rats were less prominent than in the cultured cells. With the recent increase in the use of lanthanum and other REEs, the smaller materials are receiving more attention because they are more efficient. Unfortunately, these smaller materials might more toxic than larger ones. Therefore, a comparative toxicity study between smaller and larger materials or independent separate toxicity studies are necessary to estimate the effect of lanthanum on workers who are exposed to it directly or general populations who are exposed indirectly. This study found that nano-sized lanthanum oxide was more toxic than micro-sized lanthanum in the cell culture system. Nano-sized lanthanum oxide was also more toxic than micro-sized lanthanum oxide in the rats, but the effect was less potent. To prove that lanthanum does not have adverse effects in humans, gathering toxicity data from inhalation studies is the first priority, but only a few inhalation studies have been conducted because they are generally high cost and require special equipment. While this study suggests that nano-sized lanthanum might also be more toxic than micro-sized lanthanum through inhalation in the workplace or at home, and additional inhalation studies are needed. However, the current study does provide important data for hazard assessments of lanthanum oxide and could contribute to the sound management of lanthanum.

\section{REFERENCES}

1. Heuck, F. and Hoschek, R. (1968) Cer-pneumoconiosis. Am. J. Roentgenol., 104, 780-783.

2. Rim, K.T., Koo, K.H. and Park, J.S. (2013) Toxicological evaluations of rare earths and their health impacts to workers: a literature review. Saf. Health Work, 4, 12-26.

3. British Geological Survey. (2011) Rare Earth Element. National Environment Research Council, Nottingham, pp. 1-53.

4. Geraets, L., Oomen, A.G., Schroeter, J.D., Coleman, V.A. and Cassee, F.R. (2012) Tissue distribution of inhaled micro- and nano-sized cerium oxide particles in rats: results from a 28day exposure study. Toxicol. Sci., 127, 463-473.

5. Gosens, I., Mathijssen, L.E., Bokkers, B.G., Muijser, H. and Cassee, F.R. (2014) Comparative hazard identification of nano- and micro-sized cerium oxide particles based on 28-day inhalation studies in rats. Nanotoxicology, 8, 643-653.

6. Keller, J., Wihlleben, W., Ma-Hock, L., Strauss, V., Gröters, S., Küttler, K., Weinch, K., Herden, C., Oberdörster, G., von Ravenzwaay, B. and Landsiedel, R. (2014) Time course of lung retention and toxicity of inhaled particles: Short-term exposure to nano-Ceria. Arch. Toxicol., 88, 2033-2059.

7. Toya, T., Takata, A., Okaki, N., Takaya, M., Serita, F., Yoshida, K. and Kohyama, N. (2010) Pulmonary toxicity induced by intratracheal instillation of coarse and fine particles of cerium dioxide in male rats. Ind. Health, 48, 3-11.

8. Palmer, R.J., Butenhoff, J.L. and Stevens, J.B. (1987) Cytotoxicity of the rare earth metals cerium, lanthanum, and neo- 
dymium in vitro: Comparisons with cadmium in a pulmonary macrophage primary culture system. Environ. Res., 43, 142156.

9. Cheng, J., Li, N., Cai, J., Cheng, Z., Hu, R., Zhang, Q., Wan, F., Sun, Q., Gui, S., Sang, X., Wang, L. and Hong F. (2012) Organ histopathological changes and its function damage in mice following long-term exposure to lanthanides chloride. Biol. Trace Elem. Res., 145, 361-368.

10. Cheng, J., Cheng, Z., Hu, R., Cui, Y., Cai, J., Li, N., Gui, S., Sang, X., Sun, Q., Wang, L. and Hong, F. (2014) Immune dysfunction and liver damage of mice following exposure to lanthanoids. Environ. Toxicol., 29, 64-73.

11. Takaya, M., Toya, T., Takata, A., Otaki, N., Yoshida, K. and Kohyama, N. (2005) Biological effects of rare earth oxides to respiratory organs. J. Aerosol Res., 20, 207-212.

12. Zhao, H., Cheng, Z., Hu, R., Chen, J., Hong, M., Zhou, M., Gong, X., Wang, L. and Hong, F. (2011) Oxidative injury in the brain of mice caused by lanthanoid. Biol. Trace Elem. Res., 142, 174-189.
13. OECD. (2010) Series on the safety of manufactured nanomaterials, No. 27. List of manufactured nanomaterials and list of endpoints for phase one of the sponsorship programme for the testing of manufactured nanomaterials: revision, $\mathrm{OECD}$, Paris, pp. 13.

14. Li, X.Y., Brown, D., Smith, S., MacNee, W. and Donaldson, K. (1999) Short-term inflammatory responses following intratracheal instillation of fine and ultrafine carbon black in rats. Inhalation Toxicol., 11, 709-731.

15. Sager, T.M. and Castranova, V. (2009) Surface area of particle administered versus mass in determining the pulmonary toxicity of ultrafine and fine carbon black: comparison to ultrafine titanium dioxide. Part. Fibre Toxicol., 6, 15.

16. Hong, J., Pan, X., Zhao, X., Yu, X., Sang, X., Sheng, L., Wang, X., Gui, S., Sun, Q., Wang, L. and Hong, F. (2015) Molecular mechanism of oxidative damage of lung in mice following exposure to lanthanum chloride. Environ. Toxicol., 30, 357-365. 